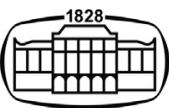

AKADÉMIAI KIADÓ

Journal of Psychedelic Studies

4 (2020) 3, 125-138

DOI:

$10.1556 / 2054.2020 .00137$

(c) 2020 The Author(s)

\title{
Culture and psychedelic psychotherapy: Ethnic and racial themes from three Black women therapists
}

\author{
MONNICA T. WILLIAMS ${ }^{1,2,3^{*}}$ (D), SARA REED ${ }^{1,2}$ and \\ JAMILAH GEORGE ${ }^{1}$
}

\author{
${ }^{1}$ Department of Psychological Sciences, University of Connecticut, Storrs, CT, USA \\ ${ }^{2}$ Behavioral Wellness Clinic, LLC, Tolland, CT, USA \\ ${ }^{3}$ School of Psychology, University of Ottawa, Ottawa, ON, Canada
}

Received: March 29, 2020 • Accepted: July 5, 2020

Published online: September 8, 2020

\section{RESEARCH ARTICLE}

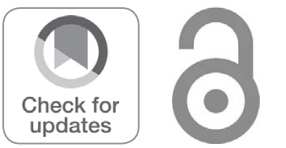

\begin{abstract}
Psychedelic medicine is an emerging field of research and practice that examines the psychotherapeutic effects of substances classified as hallucinogens on the human mind, body, and spirit. Current research explores the safety and efficacy of these substances for mental health disorders including anxiety, depression, and posttraumatic stress disorder (PTSD). Although current studies explore psychotherapeutic effects from a biomedical perspective, gaps in awareness around cultural issues in the therapeutic process are prominent. African Americans have been absent from psychedelic research as both participants and researchers, and little attention has been paid to the potential of psychedelics to address traumas caused by racialization. This paper examines cultural themes and clinical applications from the one-time use of 3,4-methylenedioxymethamphetamine (MDMA) as part of an US Food and Drug Administration (FDA)-approved clinical trial and training exercise for three African American female therapists. The primary themes that emerged across the varied experiences centered on strength, safety, connection, and managing oppression/racialization. The participants' experiences were found to be personally meaningful and instructive for how Western models of psychedelic-assisted psychotherapy could be more effective and accessible to the Black community. Included is a discussion of the importance of facilitator training to make best use of emerging material when it includes cultural, racial, and spiritual themes. A lack of knowledge and epistemic humility can create barriers to treatment for underserved populations. Implications for future research and practice for marginalized cultural groups are also discussed, including consideration of Functional Analytic Psychotherapy (FAP) as an adjunct to the psychedelic-therapy approaches currently advanced. As women of color are among the most stigmatized groups of people, it is essential to incorporate their perspectives into the literature to expand conversations about health equity.
\end{abstract}

\section{KEYWORDS}

African Americans, hallucinogens, psychedelic medicine, MDMA, psychotherapy, education, race, culture

\section{INTRODUCTION}

\section{Psychedelics in Western medicine}

Psychedelics have been used in traditional indigenous contexts for centuries for emotional health, spiritual purposes, and personal growth, but are now re-emerging in Western medicine for their potential in reducing symptoms of some of the most disabling mental health conditions. Therapeutic experimental research of psychedelics dates back to the 20th century, with drugs like Lysergic acid diethylamide (LSD), psilocybin, mescaline, and 3,4-methylenedioxymethamphetamine (MDMA) being used for a variety of indications (Costandi, 2014; Passie, 2018). Current clinical research is exploring the safety and efficacy of psychedelics for 
mental health disorders, such as posttraumatic stress disorder (PTSD), mood disorders, substance use, and end-of-life anxiety (Brown \& Alper, 2018; Ross et al., 2016; Ot'alora G et al., 2018). These drugs have been explored as stand alone treatments, such as intravenous ketamine infusion therapies (Zarate et al., 2006), and as adjuncts to psychotherapy (Mithoefer et al., 2018; Rodriguez et al., 2016; Wilkinson et al., 2017). However, very little of this research has focused on people of color, and there are no accounts that represent the experience of Black women. The purpose of this paper to report the personal accounts of three African American female clinicians who ware administered a psychedelic substance in a psychotherapeutic clinical setting to help advance our understanding of the use of psychedelic-assisted psychotherapies in different populations.

In Western clinical paradigms, psychedelic substances and traditional psychotherapy have been combined to create mental health treatments that are curative and support psychic expansion through non-ordinary states of consciousness, where the effect is potentiated by the presence of an experienced healer, therapist, or guide. For example, psilocybin is being used in combination with Acceptance and Commitment Therapy (ACT) for the treatment of Major Depressive Disorder (Sloshower et al., 2020). Ibogaine is combined with behavioral therapy in the treatment of opiate dependency (Brackenridge, 2010). Likewise, MDMA is being used in combination with psychotherapy for PTSD to facilitate trauma processing and create a context for healing within a participant's mind, body, and spirit (Mithoefer, 2015). Although psychedelic-assisted treatments are showing promise in Western medicine, researchers and clinicians must begin to examine the applicability of these protocols cross-culturally.

\section{Indigenous practices}

Most of the existing literature on psychedelic therapy is from a Eurocentric, medicalized perspective, often omitting indigenous use or discussing its origins in a detached historical manner (George, Michaels, Sevelius, \& Williams, 2020). However, many substances currently used for psychedelic medicine are derived from plants that are considered to have sacred healing properties by indigenous groups, and are still being used by those communities today. Even manufactured psychedelic substances are derived from plants, some of which have been prized for their health benefits by indigenous peoples, such as sassafras and similar spice trees, which produce safrole oil, the source of MDMA (Kemprai et al., 2020).

Cultural groups around the world make use of psychedelic healing traditions, which include the clinical management of psychedelic medicines in a spiritual context. These traditions are repositories of millennia-old medical experience and knowledge regarding best practices in the use of these substances. Such indigenous traditions constitute their own form of clinical science that provides important guidelines relevant to Western applications of psychedelics in medicine and therapy (Winkelman, 2007).
There has been much written about the indigenous use of plant medicines from Mexico and South America, but psychedelics have been used across cultures and eras. The psychedelic Soma was a central part of ancient Indian (Vedic) religiosity, and psychedelics appear to have been used in Biblical times to facilitate divine encounters by anointing priests and kings (Nemu, 2019). They have also been used for thousands of years in African culture and traditions. When Black people were enslaved in North America, Yorba women from West Africa engaged in healing practices using their knowledge of plant medicines derived from Africa (A. Williams, 2018). In Ethiopia, all plants are believed to possess some degree of medicinal usefulness, and medicinal plants occupy a central place in their traditional health care system (Doffana \& Yildiz, 2017). This includes an array of flora for medical purposes and important psychoactive plant medicines for psychological problems and more psycho-spiritual problems, such as warding off evil influences and misfortunes; Çaate (Katha edulis), buncho (Coffea arabica L.) and ţaddo (Rhamnus prinoides) are examples of some of these plant medicines (Doffana \& Yildiz, 2017).

The iboga shrub (Tabernanthe iboga) has been used for centuries in healing ceremonies and cultural rites by traditional communities in West Africa, for example among members of the Bwiti religious groups in Gabon, Cameroon, Equatorial Guinea and the Congo (Brackenridge, 2010). It is a mild stimulant in small doses, but in larger doses causes an intense psychedelic state. Iboga is the source of ibogaine, a powerful psychoactive alkaloid. Researchers in the West, found that ibogaine can significantly reduce withdrawal symptoms from opiate dependency and eliminate cravings (e.g., Brown \& Alper, 2018). This has resulted in several noteworthy clinical trials and thriving international and underground ibogaine treatment centers for opiate addiction (Labate, 2014).

In southern Africa, there is widespread reliance on ubulawu as psychoactive spiritual medicine among practitioners of traditional medicine in many communities, including the Xhosa and Zulu, to communicate with their ancestral spirits and to treat mental disturbances (Sobiecki, 2012). Ubulawu is composed of the roots of a variety of plants (e.g., Silene and Dianthus species) that are ground and made into a cold water infusion, churned to produce healing foam. Further, Bantu traditional healers use the ubulawu as part of their ritual initiation process and as a training tool for their shamanic work. It has been noted that factors such as psychological attitude, familiarization with the process, correct plant combinations, and a compatible relationship with the healer are all critical influences in the effectiveness of ubulawu (Sobiecki, 2012). The Bushmen of Dobe in Botswana use the hallucinogenic plant kwashi (Pancratium trianthum) for spiritual and healing purposes (Schultes, Hofmann, \& Ratsch, 2010). As of 2002, over 300 plants with psychoactive uses have been identified in South Africa alone, many with psychedelic properties (48 listed as visionary plants for inducing altered states of consciousness; Sobiecki, 2002). 
There are many other psychedelic medicinal traditions in Africa, but most of these have not yet been sufficiently researched to enable Westerners to fully understand or appreciate their potential. What is clear, however, is that Africans have had a long tradition of healing with psychedelic plants, used in accordance with traditional practices and experienced healers.

\section{Stigma surrounding psychedelics in Black communities}

Despite great public interest in the use of psychedelics for mental health, and traditional uses among indigenous groups, people of color in the US have shown less enthusiasm for this repopularized modality. In terms of African Americans specifically, reduced interest is evidenced by the fact that very few Black people have been included as research participants in studies of psychedelic therapy $(2.5 \%$ worldwide; Michaels, Purdon, Collins, \& Williams, 2018) and our own observations in regards to the small number of Black researchers involved in psychedelic medicine. Further, although Black and White people in the US use drugs at similar rates, recreational use of hallucinogenic drugs is far lower for African Americans than White Americans (Shalit, Rehm, \& Lev-Ran, 2019).

False stereotypes about African American drug use causes many to have increased fears about even considering psychedelics as a mode for healing and growth. Consider that Black youth use drugs at lower rates than White or Hispanic youth (Wu, Woody, Yang, Pan, \& Blazer, 2011), and Black Americans are less likely to suffer from substance use disorders than White Americans (Grant et al., 2016; Lacey et al., 2016). Nonetheless, Black Americans are 3.5 times as likely to be arrested for drug-related offenses and are 7 times more likely to be incarcerated for using drugs compared to White Americans (e.g., US DOJ, 2016; Hinton, Henderson, \& Reed, 2018).

These differential rates of punishment are not an accident. According to University of Virginia historian, Douglas Blackmon, the criminal justice system was designed to bring justice to White people and injustice to people of color (Anderson, Blackmon, Elzie, López, \& Lowery, 2017). Slave patrols were the forerunners of our police force, hired by landowners to catch runaway slaves and punish them (Turner, Giacopassi, \& Vandiver, 2006), and law enforcement today continues to carry out a version of its original mandate. Laws against drug use in the Nixon-era were intentionally designed to target Black people, as they were seen as a serious threat due to their push for Civil Rights. "Hippies" were also targeted as their opposition to the Vietnam War was attributed to the use of substances like LSD. However, drug laws were never applied evenly across racial groups, with Black Americans targeted by law enforcement and receiving longer and harsher sentences for identical violations of the law as compared to White Americans (e.g., Beckett, Nyrop, \& Pfingst, 2006). The rising perception that drugs were a Black problem fueled negative stereotypes about these communities that Black people were eager to dispel, resulting in stronger negative attitudes about drug use overall in Black communities.

The Black Church was motivated to find solutions to the crack epidemic and aligned itself with the Reagan-era "War on Drugs" as a potential solution. However, the War on Drugs became an excuse for long and harsh sentencing of Black Americans found guilty of drug infractions. Crack cocaine penalties were much more stringent than penalties for powdered cocaine use, the only difference being that Black people were more likely to use crack and White people were more likely to use cocaine. Through this process, African Americans became falsely stereotyped as addicts and dealers who were committing crimes to feed unconstrained drug habits (Williams, Gooden, \& Davis, 2012). So, the War on Drugs became a vehicle for the mass incarceration of Black Americans accused of drug infractions, and US prisons became filled with Black and Brown bodies (Alexander, 2012). There was little interest within the Black community for drugs as a means of expanding consciousness or personal growth. The focus was on preventing and reducing drug use to keep people safe, well, and out of jail.

There is no scientific literature on African Americans and psychedelics, beyond demographic correlates of usage and treatment-seeking patterns (e.g., Palamar, Mauro, Han, \& Martins, 2017). The limited research on MDMA among African Americans indicates that the drug has gained a small measure of increased popularity among Black youth, amidst much misinformation and misperception about the benefits and dangers of use. Rather than facilitating self-discovery or improving mental health, users believe MDMA can alter the effects of other drugs or potentiate sexual experiences (Rigg, 2017; Rigg \& Lawental, 2017).

\section{African American racial and cultural trauma}

Historical trauma refers to the cumulative emotional harm of an individual or generation caused by a profound traumatic experience or event. The trauma experienced by prior generations continues to result in harm to subsequent generations. The historical trauma response may include depression, substance abuse, suicidal ideation, anxiety, low self-esteem, anger, and emotional constriction (Brave Heart, 2003). Examples of historical trauma include acts of genocide, such as what happened to Native Americans and Indigenous Canadians, and to Jewish people during the Holocaust. One of the most salient examples of historical trauma in the United States is the experience of Black people in America who were kidnapped from their homes in Africa, and forced into a lifetime of servitude. These individuals were subjected to an agonizing Middle Passage, enslavement of themselves and their children, forced separation of families when children were sold, physical and sexual abuse, and forced extermination of their culture and languages. Once slavery was no longer legal, African Americans continued to experience oppression in the form of segregation, Jim Crow laws, and the unequal application of the criminal justice, which included lynchings (Alexander, 2012; DeGruy, 2007). 
At every level, the criminal justice system is heavily biased against Black people compared to White people (e.g., Beckett, Nyrop, \& Pfingst, 2006; US DOJ, 2016), and although Black Americans are $13 \%$ of the population, they comprise $35 \%$ of male inmates and $44 \%$ of female inmates (Hinton et al., 2018).

Cultural trauma occurs when members of a cultural group have been subjected to a horrendous event that etches permanent marks upon their group consciousness, marking their memories forever and changing their future identity in fundamental and irreversible ways (Alexander, Eyerman, Giesen, Smelser, \& Sztompka, 2004). Given the traumatic history of African Americans, combined with current problems such as racial profiling, mass incarceration, unchecked police violence in mass media, and daily discrimination, it should be unsurprising that cultural trauma persists (Alexander, 2012; Becket, 2006; Bor, Venkataramani, Williams, \& Tsai, 2018; Chou, Asnaani, \& Hofmann, 2012). Traumatization exists at the intersection of race and gender as well. African American women experience high rates of PTSD, which can be explained in part by the high number of traumas they experience. The National Survey of American Life found that almost half of all African American women had been assaulted, which included $17 \%$ having been raped, $20 \%$ having been sexually assaulted, and $16 \%$ having been stalked; additionally, $17 \%$ experienced a life threatening car accident, $14 \%$ had a life threatening illness, and $12 \%$ had a child with a life threatening illness (Ching, Williams, \& Taylor, 2018). Given these grim numbers, it seems clear that Black women carry a great deal of pain associated with life in America, from both past and present traumas.

The combination of historical and cultural trauma in African Americans can lead to what Dr. Joy DeGury (2007) has termed "Post Traumatic Slave Syndrome"-loss of selfesteem, anger, and internalized racism. Correspondingly, current research indicates that the experience of ongoing racism can indeed result in stress, traumatization, and even a formal diagnosis of PTSD. When racism causes or contributes to traumatization, we call it racial trauma (Williams \& Leins, 2016; Williams, Printz, Ching, \& Wetterneck, 2018).

\section{African Americans and medical research}

African Americans also have these traumas surrounding medical research, including psychedelic research. There is evidence that the risks of early era psychedelic research unduly rested on the backs of African Americans and other vulnerable populations. In examining these early studies, comparing the treatment received by White research subjects to what was experienced by people of color, inequities become evident. The Addiction Research Center (ARC) in Lexington KY, run by Dr. Harris Isbell, shared the campus with the Federal Bureau of Prisons. The research subjects were inmates, one-third White, a third "Negro" and a third "Mexican." While most people have some knowledge of the Tuskegee Syphilis Study of Untreated Syphilis that targeted Black men, few know about the facility dubbed the "Narco Farm” in Kentucky (Campbell, Olsen, \& Walden, 2008).
One study describes two groups that received LSD, one was "Negro" males convicted on drug charges who were recruited from prison and provided coercive incentives to participate in dubious LSD experiments, and the comparison group was professional White people at Cold Spring Harbor, living freely, who were not coerced but given LSD in the principal investigator's home "under social conditions designed to reduce anxiety" (Abramson, 1960). Knowing the profound influence of set, setting, and intention, these two groups undoubtedly had very different experiences. According to Edward Flowers, an African American subject in ARC experiments while incarcerated, "They used my ass and took advantage of me, you know, being a young kid and all. .." (Campbell \& Stark, 2017).

There were over 500 published studies that came out of ARC from 1935 to 1975 , testing the limits of human tolerance for psychedelics, opiates, and amphetamines on prisoners (NIDA, 1978). Dr. Isbell's studies included dangerously high and prolonged doses of LSD on his subjects. In the 1970s, ARC moved to Baltimore and became the National Institute on Drug Abuse (NIDA), after a nationwide ban on the use of federal prisoners as research subjects. These studies violated well-established guidelines for the ethical conduct of biomedical research (e.g., Nuremberg Code, Declaration of Helsinki, Belmont Report) that has never been publicly acknowledged. African Americans individually may not know the details of the crimes committed against Black communities, but the cultural memory remains (Suite, La Bril, Primm, \& Harrison-Ross, 2007).

\section{Psychedelic experiences for training of therapists}

Psychedelic-assisted psychotherapy, as practiced currently in academic research settings, involves the use of a psychedelic compound in conjunction with a specified sequence of therapy sessions that are intended to inform, shape, and support the psychedelic experience. Studies typically include three types of sessions: preparatory, medication, and integration sessions (Bogenschutz \& Forcehimes, 2016). These prepare clients for psychedelic sessions and establish the therapeutic alliance, to guide them safely during the experience and assist in the critical process of translating their experience into lasting change. Sessions generally utilize medium to high doses of a psychedelic substance during 1-3 sessions, with the intention for the client to have an intense and insightful experience supported by the therapists and further explored during integration (Nielson \& Guss, 2018).

Therapists and researchers who work with psychedelics are often questioned regarding their own use of psychedelics, with a concern that a lack of direct experience might compromise their effectiveness as therapists (Nielson \& Guss, 2018). Such experiences may be difficult to obtain given the legal prohibition against psychedelic substances, and even more so for African Americans for the reasons described previously. To facilitate instructional psychedelic experiences, the Multidisciplinary Association for Psychedelic Studies (MAPS) received US Food and Drug 
Administration (FDA) approval to proceed with a separate study for healthy volunteers. As part of the training to become an MDMA therapist, clinicians were able to receive one dose of MDMA along with psychotherapy in the same manner in which a participant would. The study was not designed to investigate the effect of the MDMA experience on clinicians, but rather to provide the opportunity for therapists in training to experience MDMA in a therapeutic setting, while collecting safety data in healthy volunteers. Some therapists have published their own individual accounts (e.g., Ching, 2020; Halberstadt, 2014), but as previously noted, there have been no accounts from African Americans and their corresponding cultural issues published in the professional literature, making this an important new area of inquiry. Women of color are among the most stigmatized groups of people in North America, where much of this work is taking place, therefore it is essential to incorporate these perspectives into the literature to expand conversations about psychedelics and health equity.

\section{METHODS}

\section{Participants and study procedures}

At the University of Connecticut Health Center (UConn), our team participated in a multisite MAPS-sponsored, FDA approved, Phase 2 open-label study for PTSD. This work focused on culturally-sensitive and respectful treatment approaches for people of color, taking into account the impact of culture and the possible need to adapt MDMA-assisted psychotherapy to culturally-specific traumas (Williams et al., 2018; Williams, Reed, \& Aggarwal, 2020).

At the UConn site, most study clinicians participated in the separate study to further their clinical training, "Phase I Placebo-Controlled, Double-Blind Crossover Study to Assess Psychological Effects of MDMA when Administered to Healthy Volunteers" (MT-1; ClinicalTrials.gov identifier: NCT01404754). MT-1 was a randomized, double-blind cross-over study, whereby all participants received MDMA during one drug session and placebo at a second session. Three MT-1 participants were Black women. Each participant had an initial preparatory visit at the investigators' offices for screening, followed by two day-long drug sessions, each including an overnight stay with a night attendant in a nearby room. Participants had an integrative session with the therapists the next morning after drug sessions, and a phone call to check in the day after. Each participant worked with two therapists, a male and a female. Between the three therapist participants, there were a total of four facilitating therapists, three of whom were White Americans and one who was a Columbian American. The study was approved by the Copernicus Institutional Review Board, and all participants provided informed consent.

\section{Methodology}

To arrive at critical themes, an iterative thematic analysis process was utilized (Vaismoradi, Jones, Turunen, \&
Snelgrove, 2016). The objective of this approach is to generate themes related to the phenomena under study that might point us toward a broader cultural experience as witnessed through a smaller number of eyes and life experiences (the phenomena-in-context). The goal is to acquire a felt sense of the experience through accounts described by different participants. To that end, each participant wrote about her experience, with a focus on the parts that felt most salient, and then condensed the accounts to approximately 950 words. An iterative process was utilized to identify themes, whereby the subjects of the study were themselves co-creators of the themes. Each participant read each account and generated themes, revising the final list until there was agreement.

What follows are the written accounts of three female African American therapists from the UConn site that participated in MT-1 in 2017 in Denver, Colorado.

\section{Psychedelic experiences}

Therapist 1: Marriage and Family Therapist. Therapist 1 is a licensed Marriage and Family Therapist and Director of Psychedelic Studies at an outpatient mental health clinic. She was also a study therapist for a psilocybin-assisted psychotherapy for Major Depressive Disorder at Yale University. She is a member of the MAPS Advisory Board and member of the Racial Equity and Access committee for the Chacruna Institute for Psychedelic Plant Medicines. She also served as a Sub-Investigator and Study Coordinator for MAPS' Phase 2 MDMA PTSD at UConn. She received her undergraduate degree in Philosophy with a bioethics concentration from the University of Louisville in Kentucky, and her M.S. in Marriage and Family Therapy from Valdosta State University in Georgia. Below she describes her MDMA experience.

"I feel like I'm dying but it's okay," I say with a smile on my face. As I lie on the couch with two therapists by my side, I observe a battle between my mind and body. My body ready to speak, each cell becoming more energized and attuned to the drug, ready for a deeper knowing of what it means to be human; and my mind, stuck, repetitive, looping on narratives of the past making sure that I "keep it together" on my journey. Soon enough, the drug sneaks past my mind's defenses, past my reflexive tendency towards control and precision, and catapults me to a place of dissolution. Defenses down, I am raw and open, experiencing the world in its Divine essence, and for the first time in my life I felt free. $\mathrm{Me}-\mathrm{a}$ young, Black woman, free. I had transcended the political realities of my race and gender and ascended to something greater-I got to be human.

No longer bound by the constraints of my political realities, I set sail on a journey that allowed me to reconnect to a place cradled by Love. I'm talking about connecting to the totality of all Life kinda place; where there is no beginning or end, where there is no separation from Love. A place I always knew existed but felt so distant from; I call that place Home. And my grandmother was the first to greet me. Imparting her wisdom not only for me, but for my mother, tears of joy filled my face. This was the first time I had felt her presence 
since her passing. "Thank you, grandma; thank you for bringing me here." I felt at peace.

After I experienced this sense of freedom and fluidity, I began to feel a heaviness in my body pulling me down into a very different story. My breath moved more slowly, a fire of emotions welling up; my body was slowing me down. Trying to put my therapist perspective on in this experience, I think there must be a technique we can do to help my body not feel so heavy. So I ask my therapists, "What can I do to speed up my body? My body is slowing me down." Little did I know coming back into this Black body, sitting with the painful internalized stories of not being enough, was the bulk of my work.

I was not happy. I was not happy at all.

Racial wounds from my past resurfaced and I had to learn how to sit with these stories in an unfiltered way. Those defenses that became a necessary part of my social development and helped me survive no longer worked. I felt lost, confused, and tired, not having the skill set to process such complexities. My personal reality, and mind, told me that I was beyond my race, gender, and traumas from the past, but my political reality, or this body, demonstrated something different. So, there I was, with my two therapists, the drug, and my wounds, trying to make sense of a new reality; a culture my body knew in a language my mind did not.

"Some moments of feedback are making me more confused, angry, and frustrated," I said to my therapists. "You all don't understand what I'm really trying to say."

"Maybe there is a part of you that doesn't want to be understood," one of the therapists says.

Silence. My mind trying to process what was said. There is nothing more than I want in life than to be understood, especially as a Black woman. Malcolm X once said, "The most disrespected, unprotected, and neglected person in America is the Black woman." I'd like to add misunderstood to that phrase too. The battle between my mind and body returns. Moments of connection were replaced by rage. I hated the parts of myself that said I wasn't enough, the society and people that reinforced this message too. I know they mean well when they say "you gotta be twice as good to get ahead," but somehow that narrative made me believe that I wasn't enough. I started to fall apart. I tried to be strong; most of the mental tricks I knew to help me distract were not working. I wanted to get back to that space of freedom but I just couldn't.

I normally cope with the stressors of life in isolation; not confiding in anyone to support me because I don't want to "burden" others, or I believe I am "strong enough" to handle it. Talking about my issues made me vulnerable, and I only knew how to be vulnerable with myself. There is a part of me that sometimes feels like I am betraying myself if I open up to others. This MDMA experience was one space where I couldn't isolate. My therapists and Spirit wouldn't let me. I had to take off my Super Woman cape and allow others to care for me - a new skill I had to learn. Love returns and this tumultuous, relentless, steadfast force did everything to protect me. And for that, I am forever grateful.

My intention going into my dosing session was that whatever happened would be for The Highest good. I believe I am still discovering what that highest good is. This MDMA therapy experience showed me - in a very embodied way the "two-ness" W.E.B. Dubois, Toni Morrison, and other writers often talk about in the Black experience. The days, weeks, and years of processing helped me realize two important truths: more Black folx deserve to feel human, free from the oppression and traumas we've endured, and that no thing can separate me from Divine Love.

Therapist 2: Clinical Psychologist. Therapist 2 is a boardcertified licensed clinical psychologist and academic researcher. She is also clinical director of an outpatient mental health facility, where she provides supervision and training to clinicians for empirically-supported cognitivebehavioral treatments. She completed her undergraduate degree from MIT, post-baccalaureate work in psychology at UCLA, and her doctorate at the University of Virginia. Her research focuses on African American mental health, culture, and psychopathology, and she is well-published on these topics. She feels passionate about improving cultural competence in the delivery of mental health care services to reduce barriers to care. She also gives diversity trainings nationally for clinical psychology programs, scientific conferences, and community organizations. Below she shares some of the insights she gained during her MT-1 experience.

As the medicine kicked in, my body felt very heavy. My two therapists suggested I lie down, and I felt myself become an immovable brick on the couch. I heard myself say it out loud and slowly, "Everything is about work. Everything I do." The words just kept coming, slowly but with purpose. "I have a schedule of stuff I do, and it's all about 'check the box.' Even my family. Even myself. It's like my life is a big to-do list and everything is check-the-box, done. Take the kids to school, check. Finish up a paper, check. Self-care, check. I like to think I am doing that for myself, but it's not, it's all work. So I can say 'yeah, I did my self-care, check.' Gym, check. Friends, check"

My family often posts pictures of me and my sisters to social media, and I always hated it. If someone had asked why, I would have said it was because my bangs were frizzy or my teeth were crooked. I figured it was just because I was a perfectionist and held myself to a higher standard. In fact, it never occurred to me that anyone might find their own child pictures positive in any way. I avoided those pictures, kept safely tucked away in an ancient photo album, and I don't show them to anyone. My childhood and my family was a mess, and these pictures reminded me of that. End of story. I thought. Until that MDMA session, where we started talking about that kid that was me. I didn't want to look at her.

I felt wisdom and compassion radiating from my therapist, as she asked if I could find love in my heart for that little girl. I said, "No, I hate her." "Can you try hating a little bit less?" she asked gently. "No!" I insisted. So why, then did I hate her so, so much? It wasn't because of anything she had done, but because of what she couldn't do. This was the key. "Because," I said with tears streaming down my face, "because she is so vulnerable." I don't know where that came from, but it all made sense. I knew deep inside that I never wanted to be that helpless again. The childlike fragility, neediness, and 
vulnerability were intolerable. I wanted to be strong all the time. As Black people, we feel we have to be strong all the time, and Black women are just strong. You can't be off your game for a minute or disaster can happen. But no one can be strong all the time, and no should have to be.

Then I saw an image of the sun. This was the heart of my experience - though it was bright yellow in the blue sky the colors stayed completely separate. I said, "The sun is yellow and the sky is blue, but there's no green." The colors should be mixing but they never do. It doesn't make sense, but it's true. I am sure my therapists thought I had completely lost my mind. For me this represented the paradox of knowing that people need people and yet feeling inside that I don't need anyone. The idea that I might need others for anything triggered intolerable feelings of brokenness that I desperately wanted to hide. And often pretending was good enough as long as I could get by, since I never thought I could ever be truly repaired. I didn't feel this as profoundly as I did in the past, but I still didn't see myself as completely whole. I felt ashamed of my shortcomings, especially my interpersonal failures, realizing that I expect to be rejected, and so I'd tell myself I don't need that person. I can't tolerate the thought of being needy.

I recognized that one of the ways I had dealt with feeling disempowered and vulnerable was to gain as many competencies as I could. I had built this big wall of competencies, of lots of things I could do really, really well to protect myself. Each glass brick in the wall was another skill or degree or ability I had mastered - knowledge of the mind, mental illness, computers, business, math, writing, sex and reproduction, etc. It also separated me from other people, and that was ok. I was the expert. Therapeutic relationships were like, "I understand everything about you while I sit safely behind my wall of competencies." Relationships were like, "I will figure out what you expect of me and I will exceed it - you will find no cracks in my wall." If there were going to be any problems, I would make sure that they were not caused by anything I did or didn't do. I was safe behind my transparent wall but at the same time, this wall had cut me off from other people. It had been a slow process to experiment with being vulnerable.

That child version of myself was so far from everything I had built. I pictured her in my mind, in a red school dress, long socks, with black pig-tails and puffy bangs. But as I looked at the image in my mind, I realized the hate was just gone. She didn't look ugly to me anymore. In fact, she reminded me of my two little brothers, who I did care about. "Can you at least have compassion for her?" the therapist asked me. Yes, I could have compassion - not love yet, but I was softening. From hate to compassion - that was a big step.

Therapist 3: Psychiatric researcher. A native of Detroit, MI, Therapist 3 obtained her Bachelor's degree from the University of Michigan and her Master of Divinity degree from Yale University at the Yale Institute of Sacred Music. She received intensive training in the Clinical Neuroscience Research Unit in the Yale Department of Psychiatry, and she is currently a doctoral student in clinical psychology. Her research interests include obsessive-compulsive disorder (OCD), namely contamination and religious OCD symptoms, along with common co-occurring disorders, such as PTSD and depression, and the neurological underpinnings of these disorders. She served as a study therapist for MAPS' Phase 2 MDMA Clinical Study of treatment-resistant PTSD among people of color at UConn and is passionate about making such treatments available to underserved populations. Below Therapist 3 recounts some of the highlights of her MT-1 experience:

When I first learned that I would have the opportunity to try MDMA as part of the MT-1 study protocol, I was so scared. As a Black woman who grew up watching my communities torn apart at the hands of gang violence, the street drug market, mass incarceration, murder, etc., drugs were not a friend of mine. Not to mention the legacy and lasting impact of the War on Drugs in the Black community, along with the over-policing and history of unethical medical practice on Black bodies, I was petrified. I thought to myself, "You mean to tell me, they want to bring $m e$, a Black female, into a clinical setting to receive a psychedelic substance?" It felt like a set-up. Were the police hiding out somewhere? Would they bother me (while doing absolutely nothing wrong, like so many others), find MDMA still in my system, and take me to jail? I didn't know. I just knew that because of the society in which we live, I did not (and still do not) feel safe. The concept was inconceivable.

On the day of my preparation session, the therapists asked, "What are your concerns or apprehensions?" I told them the truth - that I was terrified on multiple levels. We worked through that fear, but I struggled to buy into the journey. There was an immense resistance on the part of my body and my brain to trust the co-therapists or the medicine. For obvious reasons, it is easier to help others through their pain than to give adequate attention to your own.

My MT-1 experience reminded me of the ways in which I had been socialized into my own ethnic and racial identity via the appearance of familiar cultural themes. For example, I saw a particular lapa (fabric worn like a skirt in West African countries) which I recognized from my childhood African dance training. It reappeared a few different times throughout my experience and served as the most important element of one of my most impactful visions. At times, I could see myself draped in it, walking about, other times I wore it as part of a drum and dance circle, as is customary.

After what seemed like a long stretch of pain-ridden episodes, I inhaled deeply, closed my eyes, and there was nothing but darkness for a while. At that moment I felt a simultaneous terror come over me and my body. I had to lean into the unknown, which I do not like to do! But once I did, all of a sudden, I felt peace and it felt easier to breathe and like I was doing less work to escape the turmoil beneath me. When I opened my eyes, I watched myself ascend into the clear blue skies, flying above all the pain and sorrow on the ground. I didn't die or ascend into a proverbial heaven, I just started to navigate through life on a higher plane.

I was parallel to the clouds. I was so far above the ground, but I could see everything below so clearly; it was as if I had a heightened sense of vision. Beneath me was one of the lapa from my childhood, carrying me across the sky. It was a beautifully colorful and thick material. It carried me through several scenes of my ancestral history, beginning with a Southern plantation. I saw women who looked like myself and 
my mother. I hadn't known them personally, but I felt inextricably connected to them. I was somehow able to reach down and pull a few of them up with me onto the lapa. The emotions were so overwhelming that no words needed to be shared. We sat together in silence as we entered the next "scene"

My MDMA experience was full of powerful themes from my culture, dancing, music, and celebration, but also painful aspects of my past, some of which I knew far too well, others I hadn't known personally but experienced through an ancestral view. Having attended an African-centered elementary school, we were taught many African proverbs and philosophies, one of which is, "Ubuntu" meaning, "I am because we are, we are, therefore I am." I was shown that I exist because my ancestors existed first. I am also here as a result of my community, my village. The collective experience is very important in Black culture and for my experience as well. Though I was alone on this trip, I felt very much supported by my family and ancestors, particularly my Black female ancestors who exhibited strength, community, and perseverance. As such, the theme of the "strong Black woman" was prevalent, but I believe it intended to show me that I am not in this alone and that my strength comes from being in community.

During integration, I was able to process some of my experiences with the co-therapists in the room with me, but much of my understanding and processing happened in the weeks, months, and even years after my dosing session. This was partly due to needing time to process, but also because I was nervous to mention some aspects of my culture which showed up, fearing that I may be misunderstood.

Overall, I have learned so much about myself and the troubled aspects of my past which I have tucked away so neatly that no one has known to inquire. I am grateful for the work of MDMA, my team, and of course, my inner-healer, but troubled by the fact that I still do not feel safe to explore psychedelics in a healing capacity. If this treatment modality is meant to be effective for Black people, the work is different: all therapists must become preoccupied with the safety of Black bodies in these trials, less they permeate even more damage, perpetuating a vicious cycle of racialized medical trauma.

\section{RESULTS}

\section{Major themes}

All three of the MDMA-assisted experiences included cultural themes relevant to the experience of Black women in America. A main theme from Therapist 1 focused on healing deep, racialized intergenerational wounds. On one hand, she was able to experience a blissful reality beyond her race and gender; however, she also had to learn how to sit with these political realities in an unfiltered way. She notes, "As a Black woman, I had to learn the language of this White American world, the mannerisms, and the performance. I've straightened the coils from my hair and denied parts of myself just to feel like I belonged. Those defenses that became a necessary part of my social development and helped me survive in the only world I knew no longer worked."

The themes from Therapist 2 focused on the paradoxical need for human connection and dependence, in contrast to perceived need to be strong, efficient, and self-sufficient to "survive and thrive in a perilous and often hostile racist society controlled by White men and women." She found the idea of being vulnerable too threatening to tolerate, which cut her off from the vulnerable parts of her personality and interfered with important relationships.

The themes from Therapist 3 included transcendence, moving above the oppression and pain of everyday life to a higher plane, from which she could reach down and help others to also transcend. She was able to situate herself simultaneously within her ancestral community and her current African American experience, and thereby draw strength from her family, past and present. Nonetheless, she continued to feel a need to be vigilant and a lack of safety. She notes, "It has become apparent to me that we must be preoccupied with helping clients of color, Black clients in particular, to feel an immense sense of safety."

The primary themes emerging across the varied experiences include strength, safety, connection, and managing oppression/ racialization. Challenges with vulnerability also cut across the narratives. Growth from the experience centered on understanding that having needs and experiencing feelings does not equate to weakness (prominent in narratives 1 and 2), and a renewed sense of duty to provide help and healing to one's community (prominent in narrative 3 ).

\section{Experience as a training exercise}

All three therapist participants found the process of having a session of MDMA-assisted therapy, in the same manner that a client would experience it, to be helpful for better understanding the research protocol and the client experience. Navigating cultural and racial material during the MDMA sessions was also an important reminder that all participants are a product of their culture to various extents, which becomes reflected in the psychedelic experience, including past and present experiences of oppression.

The lived racial experiences and training of the facilitating therapists was salient to participant experiences, as it influenced their ability to respond to material as it was unfolding. Of the four therapists who facilitated sessions, two made statements that were culturally insensitive or microaggressive during the MDMA session, and this directly impacted two of the three Black therapist participants (Williams \& Halstead, 2019). This underscored the need for multicultural training and extreme sensitivity on the part of therapists to refrain from contributing to a participant's cultural trauma by reenacting social patterns of oppression that occur in everyday interactions outside of the treatment space (Williams et al., 2020).

\section{DISCUSSION}

\section{Psychedelic-assisted therapy for Black women}

The material that emerged from the MDMA-assisted psychotherapy sessions was filled with themes that are particularly salient for Black women in America, including cultural 
trauma, spiritual connection to ancestors, care for community, and the Strong Black Woman archetype - an intersectional conceptualization of Black womanhood. This archetype derives from slavery, when Black women had to be strong in order to survive and protect their children in a brutal environment of forced physical, emotional, and sexual servitude. The Strong Black Woman has become "a cultural ideal that portrays Black women as strong, self-reliant, nurturing, resilient, and invulnerable to psychological or physical challenges" (Baker, Buchanan, Mingo, Roker, \& Brown, 2015, p. 53). Black women may struggle with how much to identify with this ideal due to its conflicting positive and negative and characteristics. Although a focus on inner strength can be empowering, adopting this archetype perpetuates problems such as being overworked, undertreated for mental health needs, neglectful of self-care, and cut-off from nurturing from others. It can also interfere with the emotional vulnerability needed to forge deep, mutually reciprocal relationships.

One important avenue for understanding some of the other themes may lie in cultural differences in approaches to understanding the self. The North American concept of the person centers on individualism, where each person is considered autonomous and uniquely deserving the free pursuit of their own private goals; this "egocentric" notion of the person leads individuals to think about their identity primarily in terms of personal history and achievements (Kirmayer, 2007). However African cultures typically have more of a "cosmocentric" sense of self, and may therefore narrate their identity in relation to ancestors, spirits, or larger cosmic forces. Of course, the different ways of construing the self are not mutually exclusive, as egocentric and cosmocentric views may exist simultaneously (Kirmayer, 2007).

Nonetheless, as noted by Kpanake (2018), African cultures generally have a more spiritual and relational-oriented perspective of the self, in which an individual manifests "personhood through connections to three distinct forms of agency: (a) spiritual agency, including God, ancestors, and spirits that influence the person; (b) social agency, including the family, the clan, and the community, with extension to humanity; and (c) self-agency, which is responsible for the person's inner experience" (p. 198). These three forms of agency were all apparent in one or more of the narratives provided by participants, reflecting their meaningful and important connection to African culture.

Understanding the self from the perspective of a Black woman requires consideration of intersectionality as well. Black women often experience oppression by being both Black and a woman. They may not be able to separate these two facets of their identity into distinct pieces, but rather conceptualize themselves holistically. Without this framework, one can misunderstand or misinterpret important aspects that are salient to her experience.

\section{Dangers of culturally uninformed therapy}

When therapists are unable to make use of cultural material it can represent a lost opportunity for healing, but it is much worse when therapists actively cause harm. It has been recognized for some time that racially charged materials can provoke violence from clinicians in the form of microaggressions or other harmful actions or inactions, as therapists struggle to manage their own psychic woundedness around issues of race (Comaz-Diaz \& Jacobsen, 1991; Kanter et al., 2020). Race relations in the US, Canada, and many other Western nations operate within a system whereby people of color are expected to maintain White comfort by remaining silent about past and present experiences of racial oppression (DiAngelo, 2011; Kanter et al., 2019). This expectation often extends into the mental health care frame, and it is thought to represent a major barrier to treatment for people of color, as good therapy requires an open trusting dialog. Further, in a typical outpatient mental health setting, if an African American client is harmed by a therapist, the client can use their generally well-developed defenses against racism and choose to engage at a superficial level or not at all, or even walk out. In contrast, when under the influence of a psychedelic, the client may not leave the session for several hours and may not be able to access their typical defenses to protect against emotional harm. Further, the heart-opening properties of MDMA specifically may make clients who are seeking healing from racial traumas particularly vulnerable to further emotional injury. This represents at least two distinct kinds of abuse, abuse of authority and abuse aided by an intoxicating substance (Dawson, 2019). This could be compared to the devastating experience of a client seeking healing from the trauma of rape only to be subjected to sexual advances from a therapist while in a physically vulnerable or even helpless state.

\section{Training for therapists and guides}

Because of the extreme vulnerability of patients during psychedelic-assisted psychotherapy, all therapy providers and supervisors should have basic competencies in working ethically and skillfully with people of color. As noted by Williams et al. (2020), essential skills include, the ability to (1) identify normal cultural variations in the expression of psychopathology and personality, (2) recognize trauma related to the experiences of racism and other forms of oppression, (3) develop good rapport with people of color by appropriately expressing caring, empathy, and respect, (4) comfortably engage in discussions about racial topics, and (5) identify and examine personal biases as they relate to ethnic and racial differences, with an ongoing action plan to address any areas of difficulty. All therapy providers conducting psychedelic therapies should be competent in these areas prior to working with people from different ethnic groups. Skill in cross-racial work is critical given the very limited number of psychedelic therapists of color.

Functional Analytic Psychotherapy (FAP) is a therapeutic approach rooted in the contextual behavioral tradition (Hayes, Barnes-Holmes, \& Wilson, 2012) that focuses on the therapeutic relationship as the agent of change to improve relationships (Tsai et al., 2009). FAP promotes intrapersonal awareness as well as interpersonal awareness between the client and therapist equally for a strong and authentic connection. This approach prompts FAP therapists to take interpersonal 
risks by experiencing, processing, and disclosing reactions to the client as they occur in-session in the service of client growth, and it prompts therapists to encourage their clients to do the same. When the client engages in courageous self-expression in FAP sessions, the therapist in turn responds with genuine feedback to increase the intimacy of the exchange. This vulnerability and immediacy serves as a model to help the client improve connections with others, which is an important transdiagnostic outcome (Wetterneck \& Hart, 2012).

In this context, inadvertent insensitivities and microaggressions committed by therapists present a barrier to fundamental and necessary intimate, trusting, and safe transactions. Within FAP this could become an opportunity for therapist growth around racial anxieties and client growth in successful assertion of needs, which would ideally lead to a celebration of a client's expression of their full self as an ethnic and cultural being. FAP is particularly well-suited for culturally-sensitive practice because of its focus on the relationship as a primary change mechanism, and FAP is flexible enough to be used for understanding behaviors across cultures and ethnicities (Vanderburghe, 2008). Therapists are allowed to admit that they do not have all the answers and may not fully understand the experience of racial oppression, which paradoxically bolsters trust and genuine connection with the client. And, as therapists are able to confront their own assumptions and biases, they become more culturally sensitive and attuned to feedback from their diverse clients (Miller, Williams, Wetterneck, Kanter, \& Tsai, 2015). Thus, FAP may be well-suited for MDMA-assisted psychotherapy with people of color, given the focus on establishing a quality emotional connection (Luoma, Sabucedo, Eriksson, Gates, \& Pilecki, 2019; Williams et al., 2020).

Since the accounts described in this paper occurred, MAPS has made efforts to further the cultural competence of its therapists, including a series of trainings for independent raters, that was recorded and subsequently made available to study therapists (Reed, 2019; Williams et al., 2020). Further, in August 2019, two of the authors organized and co-led a community conference and special training for therapists of color, which was grant-funded by the Open Society Foundation and other donors and implemented by MAPS (Williams \& Labate, 2020). These are essential early steps in improving treatment for people of color, however important gaps remain. For example, at MAPS there are almost no approved supervisors able to provide culturallyinformed oversight to new therapists who might require guidance in this area. Apart from MAPS, we are aware of no other sponsors or research teams attending to this aspect of the work (Williams et al., 2020), however one of the only certified training programs for psychedelic therapies, the California Institute of Integral Studies, had put some successful measures in place to increase admissions for trainees of color.

\section{Addressing misgivings}

Some may be concerned that exposing people to psychedelics may be simply introducing a new approach for escaping from problems as opposed to working through them in a clinical setting. People may fear this process encourages potential drug misuse among patients and clinicians by trying psychedelics in a clinical setting. Indeed, the therapist participants featured here each had private reservations about participating in MT-1 for a variety of reasons. It is important to understand that all medications have the potential for healing or abuse, depending on how they are used, and psychedelics are no exception. That being said, the data indicate that compared to other substances, psychedelics are generally safe, with low addiction potential, and even recreational use is correlated to few negative outcomes (Johansen \& Krebs, 2015).

Further, psychedelic-assisted therapy is hard work and should not be considered an escape or shortcut to healing. All three therapists spent considerable time and effort processing their experiences alone and with others to integrate what was learned into their lives for personal growth and individual healing from racial stress and trauma.

\section{Reclaiming our cultural birthright}

As described previously, there is a rich tradition of plant medicines and spirituality in Africa, and African spiritual themes were prominent in two of the three narratives. As such, people from the African diaspora may especially benefit from psychedelics within a culturally-appropriate framework. Two of the participants have started providing culturally-informed psychedelic-assisted psychotherapy as a means of treating racial trauma in an outpatient mental health clinic. In our experience, many African Americans are fearful of psychedelic medicines and the vulnerability that comes with being in an altered state. Certainly, these treatments can be unsafe without skilled providers or caring therapists to guide clients on their journeys. But these medicines are part of our cultural birthright, and African Americans deserve the same access to the healing potential of psychedelics that our ancestors have benefitted from and continue to benefit from in Africa today.

\section{Limitations and future directions}

Because this study chose to focus on the voices of African American women, the experiences described cannot be assumed to generalize to African American males or even Black people worldwide. More research is needed to amplify the voices of people from other racial and ethnic groups and those with other marginalized identities to better understand psychedelic experiences cross-culturally. As more narratives become available, it would be interesting and important to compare them across populations to better understand how culture influences the psychedelic experience.

\section{CONCLUSION}

There is a great potential for psychedelic therapy to address the mental health needs of people of color, who experience the same mental health needs as White people, in addition 
to the reality of intergenerational cultural trauma for many ethnic groups and intersectional trauma for women of color. Barriers to safe and effective psychedelic care include a lack of clinicians who are able to navigate challenging racial material in a non-violent matter, and a lack of awareness surrounding how to optimally utilize cultural, spiritual, and historical material as it arises. These problems point to a need for more therapists of color who understand nuanced cultural issues as they pertain to specific ethnic groups, as well as better multicultural training for all therapists, which should include education about microaggressions and the therapeutic use of FAP (e.g., Kanter et al., 2020; Williams, Reed, \& Aggarwal, 2020). Some important efforts in this area have begun, but much more is needed and on a larger scale.

There is an urgent need to address many unanswered questions relevant to people of color. Future studies might examine the outcomes of psychedelic therapy with and without the added therapeutic connection provided by FAP, to explore how it may reduce the prevalence and impact of covert racism during treatment (e.g., Miller et al., 2015). Work is needed to better understand and address the role of culture in set and setting for best outcomes (e.g., Neitzke-Spruill, 2020). Although this paper has focused on the psychotherapeutic experience, future research also needs to examine how different psychedelic compounds may differentially affect ethnic groups to help inform dosing and management of side-effects (e.g., Papaseit, Torrens, Pérez-Mañá, Muga, \& Farré, 2018). Additionally, more work needs to be done to educate and inform people of color about psychedelic options for healing, and advocate for inclusion.

The use of psychedelics has not always been safe for Black Americans, but as psychedelics move into the mainstream there may be an opportunity for the African diaspora to come together as a people, create safe spaces, and become empowered to reclaim psychedelic healing for Black communities (Williams, 2020). Creation of new rituals and a spiritual path surrounding psychedelic healing where it is yet undefined and could be an important means of reconnecting to beneficial ancestral practices in a modern context, thus paving the way for greater access to mental health for Black people everywhere as psychedelics become legal medicines.

Conflict of interest: The authors have no conflicts of interest to report.

Acknowledgments: The authors wish to thank Marcela Ot'alora for her therapeutic support and guidance in these experiences. The author also wishes to thank the non-profit organization, Multidisciplinary Association for Psychedelic Studies (MAPS; www.maps.org), who sponsored and funded "A Phase 1 Placebo-Controlled, Double-Blind, Multi-Site Crossover Study to Assess Psychological Effects of MDMA when Administered to Healthy Volunteers" (MT-1; ClinicalTrials.gov identifier: NCT01404754).

\section{REFERENCES}

Abramson, H. A. (1960) Lysergic Acid Diethylamide (LSD-25). XXXI. Comparison by questionnaire of psychotomimetic activity of congeners on normal subjects and drug addicts. Journal of Mental Science, 106, 1120-1123.

Alexander, M. (2012). The new Jim Crow: Mass incarceration in the age of colorblindness. The New Press.

Alexander, J., Eyerman, R., Giesen, B., Smelser, N., \& Sztompka, P. (2004). Toward a theory of cultural trauma. In Cultural Trauma and collective identity (pp. 1-30). Berkeley, Los Angeles and London: University of California Press. Retrieved February 8, 2020, from www.jstor.org/stable/10.1525/j.ctt1pp9nb.4.

Anderson, C., Blackmon, D. A., Elzie, J. López, I. H, \& Lowery, W. (2017, March 3). Understanding the problem. Policing color: Black, Brown, and blue forum. Panel, Duke University, School of Law, NC.

Baker, T. A, Buchanan, N. T., Mingo, C. A., Roker, R., \& Brown, C. S. (2015). Reconceptualizing successful aging among black women and the relevance of the strong black woman archetype. The Gerontologist, 55(1), 51-57. https://doi.org/10.1093/geront/gnu105.

Beckett, K., Nyrop, K., \& Pfingst, L. (2006). Race, drugs, and policing: Understanding disparities in drug delivery arrests. Criminology: An Interdisciplinary Journal, 44(1), 105-137. https://doi.org/10.1111/j.1745-9125.2006.00044.x.

Bogenschutz, M. P., \& Forcehimes, A. A. (2016). Development of a psychotherapeutic model for psilocybin-assisted treatment of alcoholism. Journal of Humanistic Psychology, 57(4), 389-414. https://doi.org/10.1177/0022167816673493.

Bor, J., Venkataramani, A. S., Williams, D. R., \& Tsai, A. (2018). Police killings and their spillover effects on the mental health of Black Americans: A population-based, quasi-experimental study. The Lancet, 392, 302-310. https://doi.org/10.1016/S01406736(18)31130-9.

Brackenridge, P. (2010). Ibogaine therapy in the treatment of opiate dependency. Drugs \& Alcohol Today, 10(4), 20-25. https://doi. org/10.5042/daat.2010.0724.

Brave Heart, M. (2003). The historical trauma response among natives and its relationship with substance abuse: A Lakota illustration. Journal of Psychoactive Drugs, 35(1), 7-13.

Brown, T. K., \& Alper, K. (2018). Treatment of opioid use disorder with ibogaine: Detoxification and drug use outcomes. The American Journal of Drug and Alcohol Abuse, 44(1), 24-36. https://doi.org/10.1080/00952990.2017.1320802.

Campbell, N. D., Olsen, J. P., \& Walden, L. (2008). The narcotic farm: The rise and fall of America's first prison for drug addicts. London and New York: Abrams.

Campbell, N. D., \& Stark, L. (2017). Making up 'vulnerable' people: Human subjects and the subjective experience of medical experiment. In K. Brzechczyn (ed.), Towards a revival of analytical philosophy of history (pp. 225-253). Boston: Brill Rodopi.

Ching, T. H. W., Williams, M. T., \& Taylor, R. J. (2018, November). Gender differences in lifetime trauma exposure among African Americans and Black Caribbeans. Poster session at the 52nd annual convention of the association of behavioral and cognitive therapies, Washington, DC. 
Chou, T., Asnaani, A., \& Hofmann, S. G. (2012). Perception of racial discrimination and psychopathology across three U.S. Ethnic minority groups. Cultural Diversity and Ethnic Minority Psychology, 18(1), 74-81.

Comas-Diaz, L., \& Jacobsen, F. (1991). Ethnocultural transference and countertransference in the therapeutic dyad. American Journal of Orthopsychiatry, 61(3), 392-402.

Costandi, M. (2014). A brief history of psychedelic psychiatry. The Psychologist, 27(9), 714-715.

Dawson, A. (2019, May 22). Psychedelics, sex, and consent: A brief history. Chacruna Institute. Retrieved from https://chacruna. net/psychedelics-sex-and-consent-a-brief-history/.

DeGruy, J. (2007). Post traumatic slave Syndrome: America's Legacy of enduring Injury and healing (Revised and Updated Edition). Joy Degruy Publications, Inc.

DiAngelo, R. (2011). White fragility. The International Journal of Critical Pedagogy, 3(3), 54-70.

Doffana, Z. D., \& Yildiz, F. (2017). Sacred natural sites, herbal medicine, medicinal plants and their conservation in Sidama, Ethiopia. Cogent Food \& Agriculture, 3(1). https://doi.org/10. 1080/23311932.2017.1365399.

George, J. R., Michaels, T. I., Sevelius, J., \& Williams, M. T. (2020). The psychedelic renaissance and the limitations of a Whitedominant medical framework: A call for indigenous and ethnic minority inclusion. Journal of Psychedelic Studies, 4(1), 4-15. https://doi.org/10.1556/2054.2019.015.

Grant, B. F., Saha, T. D., Ruan, W. J., Goldstein, R. B., Chou, S. P., Jung, J., et al. (2016). Epidemiology of DSM-5 drug use disorder: Results from the National Epidemiologic Survey on alcohol and related conditions-III. JAMA Psychiatry, 73(1), 39-47. https://doi.org/10.1001/jamapsychiatry.2015.2132.

Halberstadt, N. (2014). MDMA-assisted psychotherapy: A view from both sides of the couch. MAPS Bulletin (Special Edition), 24(1), 4-6.

Hayes, S. C., Barnes-Holmes, D., \& Wilson, K. G. (2012). Contextual behavioral science: Creating a science more adequate to the challenge of the human condition. Journal of Contextual Behavioral Science, 1, 1-16.

Hinton, E., Henderson, L., \& Reed, C. (2018, May). An unjust burden: The disparate treatment of black Americans in the criminal justice system. Vera evidence brief. Vera Institute of Justice. Retrieved from https://www.vera.org/downloads/ publications/for-the-record-unjust-burden-racial-disparities.pdf.

Johansen, P.-Ø., \& Krebs, T. S. (2015) Psychedelics not linked to mental health problems or suicidal behavior: A population study. Journal of Psychopharmacology, 29(3), 270-279. https:// doi.org/10.1177/0269881114568039.

Kanter, J. W., Rosen, D. C., Manbeck, K. E., Branstetter, H., Kuczynski, A., Corey, M. D., et al. (2020). Addressing microaggressions in racially charged patient-provider interactions: A pilot randomized trial. BMC Medical Education, 20(88), 1-14. https://doi.org/10.1186/s12909-020-02004-9.

Kanter, J. W., Rosen, D. C., Manbeck, K. E., Kuczynski, A. M., Corey, M.D., \& Branstetter, H. M. L. (2019). Using contextualbehavioral science to understand racism and bias, chapter 6 . In M. T. Williams, D. C. Rosen, \& J. W. Kanter (Eds.), Eliminating race-based mental health disparities: Promoting equity and culturally responsive care across settings. Oakland, CA: New Harbinger Books.

Kemprai, P., Mahanta, B. P., Sut, D., Barman, R., Banik, D., Lal, M., et al. (2020). Review on safrole: Identity shift of the "candy shop" aroma to a carcinogen and deforester. Flavour and Fragrance Journal, 35(1), 5-23. https://doi.org/10.1186/s12909020-02004-9.

Kirmayer, L. J. (2007). Psychotherapy and the cultural concept of the person. Transcultural Psychiatry, 44(2), 232-257. https:// doi.org/10.1186/s12909-020-02004-9.

Kpanake, L. (2018). Cultural concepts of the person and mental health in Africa. Transcultural Psychiatry, 55(2), 198-218. https://doi.org/10.1177/1363461517749435.

Labate, B. (2014). Journey to find iboga. Erowid. Retrieved from http://erowid.org/plants/iboga/iboga_article1.shtml.

Lacey, K. K., Mouzon, D. M., Govia, I. O., Matusko, N., ForsytheBrown, I., Abelson, J. M., et al. (2016). Substance abuse among blacks across the diaspora. Substance Use \& Misuse, 51(9), 1147-1158. https://doi.org/10.3109/10826084.2016.1160124.

Luoma, J. B., Sabucedo, P., Eriksson, J., Gates, N., \& Pilecki, B. C. (2019). Toward a contextual psychedelic-assisted therapy: Perspectives from acceptance and commitment therapy and contextual behavioral science. Journal of Contextual Behavioral Science, 14, 136-145. https://doi.org/10.1016/j.jcbs.2019. 10.003 .

Michaels, T. I., Purdon, J., Collins, A., \& Williams, M. T. (2018). Inclusion of people of color in psychedelic-assisted psychotherapy: A review of the literature. BMC Psychiatry, 18(245), 19. https://doi.org/10.1186/s12888-018-1824-6.

Miller, A., Williams, M. T., Wetterneck, C. T., Kanter, J., \& Tsai, M. (2015). Using functional analytic psychotherapy to improve awareness and connection in racially diverse client-therapist dyads. The Behavior Therapist, 38(6), 150-156.

Mithoefer, M. C. (2015, August). A manual for MDMA-assisted psychotherapy in the treatment of posttraumatic stress disorder, Version 7: 19. Santa Cruz, CA: Multidisciplinary Association for Psychedelic Studies (MAPS). Retrieved from https://maps.org/research-archive/mdma/MDMA-AssistedPsychotherapy-Treatment-Manual-Version7-19Aug15FINAL.pdf.

Mithoefer, M. C., Mithoefer, A. T., Feduccia, A. A., Jerome, L., Wagner, M., Wymer, J., et al. (2018). 3,4-Methylenedioxymethamphetamine (MDMA)-assisted psychotherapy for posttraumatic stress disorder in military veterans, firefighters, and police officers: A randomised, double-blind, dose-response, phase 2 clinical trial. The Lancet Psychiatry, 5(6), 486-497. https://doi.org/10.1016/S2215-0366(18)30135-4.

National Institute on Drug Abuse (NIDA). (1978). Annotated Bibliography of Papers from the addiction research center 193575. U.S. Department of Health, Education, and Welfare. Public Health Service Alcohol, Drug Abuse, and Mental Health Administration. Rockville, Maryland. Retrieved from https:// www.ncjrs.gov/pdffiles1/Digitization/62807NCJRS.pdf.

Neitzke-Spruill, L. (2020). Race as a component of set and setting: How experiences of race can influence psychedelic experiences. Journal of Psychedelic Studies, 4(1), 51-60. https://doi.org/10. 1556/2054.2019.022. 
Nemu, D. (2019). Getting high with the most high: Entheogens in the old testament. Journal of Psychedelic Studies, 3(2), 117-132. https://doi.org/10.1556/2054.2019.004.

Nielson, E., \& Guess, J. (2018). The influence of therapists' firsthand experience with psychedelics on psychedelic-assisted psychotherapy research and therapist training. Journal of Psychedelic Studies, 2(2), 64-73. https://doi.org/10.1556/2054.2018. 009.

Ot'alora G, M., Grigsby, J., Poulter, B., Van Derveer, J. W., Giron, S. G., Jerome, L., et al. (2018). 3,4-Methylenedioxymethamphetamine-assisted psychotherapy for treatment of chronic posttraumatic stress disorder: A randomized phase 2 controlled trial. Journal of Psychopharmacology, 32(12), 1295-1307.

Palamar, J. J., Mauro, P. M., Han, B. H., \& Martins, S. S. (2017). Shifting characteristics of ecstasy users ages 12-34 in the United States, 2007-2014. Drug and Alcohol Dependence, 181, 20-24. https://doi.org/10.1016/j.drugalcdep.2017.09.011.

Papaseit, E., Torrens, M., Pérez-Mañá, C., Muga, R., \& Farré, M. (2018). Key interindividual determinants in MDMA pharmacodynamics. Expert Opinion on Drug Metabolism \& Toxicology, 14(2), 183-195. https://doi.org/10.1080/17425255.2018.1424832.

Passie, T. (2018). The early use of MDMA ('Ecstasy') in psychotherapy (1977-1985). Drug Science, Policy and Law, 4, 1-19. https://doi.org/10.1177/2050324518767442.

Reed, S. (2019, Spring). Health equity in psychedelic medicine: Advancing practices for people of color. MAPS Bulletin, 29 (1), 50-51. Retrieved from https://maps.org/news/bulletin/articles/ 436-maps-bulletin-spring-2019-vol-29,-no-1/7719-healthequity-in-psychedelic-medicine-advancing-practices-forpeople-of-color-spring-2019.

Rigg, K. K. (2017). Motivations for using MDMA (Ecstasy/Molly) among African Americans: Implications for prevention and harm-reduction programs. Journal of Psychoactive Drugs, 49(3), 192-200. https://doi.org/10.1080/02791072.2017.1305518.

Rigg, K. K., \& Lawental, M. (2018). Perceived risk associated with MDMA (Ecstasy/Molly) use among African Americans: What prevention and treatment providers should know. Substance Use \& Misuse, 7(53), 1076-1083. https://doi.org/10.1080/ 10826084.2017.1392985.

Rodriguez, C. I., Wheaton, M., Zwerling, J., Steinman, S. A., Sonnenfeld, D., Galfalvy, H., et al. (2016). Can exposure-based CBT extend the effects of intravenous ketamine in obsessivecompulsive disorder? An open-label trial. The Journal of Clinical Psychiatry, 77(3), 408-409.

Ross, S., Bossis, A., Guss, J., Agin-Liebes, G., Malone, T., Cohen, B., et al. (2016). Rapid and sustained symptom reduction following psilocybin treatment for anxiety and depression in patients with life-threatening cancer: A randomized controlled trial. Journal of Psychopharmacology, 30(12), 1165-1180. https://doi.org/10. $1177 / 0269881116675512$.

Schultes, R. E., Hofmann, A., \& Ratsch, C. (2010). Plants of the gods: Their sacred, healing, and hallucinogenic powers. Rochester, VT: Healing Arts Press.

Sobiecki, J. F. (2002). A preliminary inventory of plants used for psychoactive purposes in southern African healing traditions. Transactions of the Royal Society of South Africa, 57(1-2), 1-24.

Shalit, N., Rehm, J., \& Lev-Ran, S. (2019). Epidemiology of hallucinogen use in the U.S. results from the National epidemiologic survey on alcohol and related conditions III. Addictive Behaviors, 89, 35-43. https://doi.org/10.1016/j.addbeh.2018.09.020.

Sloshower, J., Guss, J., Krause, R., Wallace, R., Williams, M., \& Reed, S., et al. (2020). Psilocybin-assisted therapy of major depressive disorder using Acceptance and Commitment Therapy as a therapeutic frame. Journal of Contextual Behavioral Science, 15, 12-19.

Sobiecki, J. (2012). Psychoactive ubulawu spiritual medicines and healing dynamics in the initiation process of southern Bantu diviners. Journal of Psychoactive Drugs, 44(3), 216-223.

Suite, D. H., La Bril, R., Primm, A., \& Harrison-Ross, P. (2007). Beyond misdiagnosis, misunderstanding and mistrust: Relevance of the historical perspective in the medical and mental health treatment of people of color. Journal of the National Medical Association, 99(8), 879.

Tsai, M., Kohlenberg, R. J., Kanter, J. W., Kohlenberg, B., Follette, W. C., \& Callaghan, G. M. (2009). A guide to functional analytic psychotherapy: Awareness, courage, love, and behaviorism. New York, NY: Springer.

Turner, K. B., Giacopassi, D., \& Vandiver, M. (2006). Ignoring the past: Coverage of slavery and slave patrols in criminal justice texts. Journal of Criminal Justice Education, 17(1), 181-195.

United States Department of Justice (DOJ). (2016, August 10). Investigation of Baltimore City Police Dept. DOJ Civil Rights Division. Retrieved from https://www.justice.gov/crt/file/ 883296/download.

Vaismoradi, M., Jones, J., Turunen, H., \& Snelgrove, S. (2016). Theme development in qualitative content analysis and thematic analysis. Journal of Nursing Education and Practice, 6(5), 100-110.

Vandenberghe, L. (2008). Culture-sensitive functional analytic psychotherapy. The Behavior Analyst, 31(1), 67-79.

Wetterneck, C. T. \& Hart, J. M. (2012). Intimacy is a transdiagnostic problem for cognitive behavior therapy: Functional analytic psychotherapy is a solution. International Journal of Behavioral Consultation and Therapy, 7(2-3), 167-176.

Wilkinson, S. T., Wright, D., Fasula, M. K., Fenton, L., Griepp, M., \& Ostroff, R. B. (2017). Cognitive behavior therapy may sustain antidepressant effects of intravenous ketamine in treatmentresistant depression. Psychotherapy and Psychosomatics, 86, 162-167.

Williams, A. (2018). Women, spirituality, and plant-based medicines. Chacruna Institute. Retrieved from https://chacruna.net/ women-spirituality-and-plant-based-medicines/.

Williams, M. T. (2020, March 23). Why black people should embrace psychedelic healing: Reclaiming our cultural birthright. Chacruna Institute. Retrieved from https://chacruna.net/whyblack-people-should-embrace-psychedelic-healing-reclaimingour-cultural-birthright/.

Williams, M. T., Gooden, A. M., \& Davis, D. (2012). African Americans, European Americans, and pathological stereotypes: An African-centered perspective. In G. R. Hayes, \& M. H. Bryant (Eds.), Psychology of culture (pp. 25-46). Hauppauge, NY: Nova Science Publishers. ISBN-13: 978-1-62257-274-8.

Williams, M., \& Halstead, M. (2019). Racial microaggressions as barriers to treatment in clinical care. Directions in Psychiatry, 39(4), 265-280. 
Williams, M. T., \& Labate, B. (2020). Diversity, equity, and access in psychedelic medicine. Journal of Psychedelic Studies, 4(1), 1-3. https://doi.org/10.1556/2054.2019.032.

Williams, M. T., \& Leins, C. (2016). Race-based trauma: The challenge and promise of MDMA-assisted psychotherapy. Multidisciplinary Association for Psychedelic Studies (MAPS) Bulletin, 26(1), 32-37.

Williams, M. T., Printz, D., Ching, T., \& Wetterneck, C. T. (2018). Assessing PTSD in ethnic and racial minorities: Trauma and racial trauma. Directions in Psychiatry, 38(3), 179-196.

Williams, M. T., Reed, S., \& Aggarwal, R. (2020). Culturallyinformed research design issues in a study for MDMA-assisted psychotherapy for posttraumatic stress disorder. Journal of Psychedelic Studies, 4(1), 40-50. https://doi.org/10.1556/2054. 2019.016.
Winkelman, M. J. (2007). Shamanic guidelines for psychedelic medicine. In M. J. Winkelman, \& T. B. Roberts (Eds.), Psychedelic medicine: New evidence for hallucinogenic substances as treatments, (Vol. 2, pp. 143-167). Praeger Publishers/Greenwood Publishing Group.

Wu, L. T., Woody, G. E., Yang, C., Pan, J. J., \& Blazer, D. G. (2011). Racial/ethnic variations in substance-related disorders among adolescents in the United States. Archives of General Psychiatry, 68(11), 1176-1185. https://doi.org/10.1001/archgenpsychiatry. 2011.120.

Zarate, C. A., Singh, J. B., Carlson, P. J., Brutsche, N. E., Ameli, R., Luckenbaugh, D. A., et al. (2006). A randomized trial of an N-Methyl-D-Aspartate antagonist in treatmentresistant major depression. Archives of General Psychiatry, 63, 856-864. 